MATEC Web of Conferences 33, 04004 (2015)

DOI: $10.1051 /$ matecconf/ 20153304004

(c) Owned by the authors, published by EDP Sciences, 2015

\title{
Powder metallurgy and mechanical alloying effects on the formation of thermally induced martensite in an FeMnSiCrNi SMA
}

\author{
Bogdan Pricop ${ }^{1}$, Elena Mihalache ${ }^{1}$, Monica-Nicoleta Lohan ${ }^{1}$, Bogdan Istrate ${ }^{1}$, Mihai Mocanu ${ }^{1}$, Burak Ozkal ${ }^{2}$, \\ Leandru-Gheorghe Bujoreanu ${ }^{1, a}$ \\ ${ }^{1}$ Faculty of Materials Science and Engineering, The "Gheorghe Asachi" Technical University of laşi, Bd. D. Mangeron 67, \\ 700050 lași, Romania \\ ${ }^{2}$ Particulate Materials Laboratory, Metallurgical and Materials Engineering Department, Istanbul Technical University, \\ 34469 Maslak, Istanbul, Turkey
}

\begin{abstract}
By ingot metallurgy (IM, melting, alloying and casting), powder metallurgy (PM, using as-blended elemental powders) and mechanical alloying (MA of $50 \%$ of particle volume), three types of FeMnSiCrNi shape memory alloy (SMA) specimens were fabricated, respectively. After specimen thickness reduction by hot rolling, solution treatments were applied, at 973 and $1273 \mathrm{~K}$, to thermally induce martensite. The resulting specimens were analysed by X-ray diffraction (XRD) and scanning electron microscopy (SEM), in order to reveal the presence of $\varepsilon$ (hexagonal close-packed, hcp) and $\alpha^{\prime}$ (body centred cubic, bcc) thermally induced martensites. The reversion of thermally induced martensites, to $\gamma$ (face centred cubic, fcc) austenite, during heating, was confirmed by dynamic mechanical analysis (DMA), which emphasized marked increases of storage modulus and obvious internal friction maxima on DMA thermograms. The results proved that the increase of porosity degree, after PM processing, increased internal friction, while MA enhanced crystallinity degree.
\end{abstract}

\section{Introduction}

Fe-Mn-Si SMAs have been intensively studied ever since their discovery in 1982, by A. Sato et al. [1]. Different alloying elements were added in order to improve material's properties for commercial purposes and thus two main compositions were obtained: Fe-28 Mn-6 Si-5 $\mathrm{Cr}$ [2] and Fe-14 Mn-6 Si-9 Cr-5 Ni [3] (mass. \%, as all compositions will be listed hereinafter). The inventory of previously reported drawbacks of ingot metallurgy (IM) processing of Fe-Mn-Si-Cr-Ni alloys [4-8] suggest that an alternative approach for producing these alloys could be powder metallurgy (PM) which has been successfully applied to other SMAs, such as $\mathrm{Ti}-\mathrm{Ni}$, or to $\mathrm{Cu}$ base alloys [9].

PM processing enables to obtain accurate composition and MA has the potential to increase the compactness and to better control grain size, thus avoiding most of IM drawbacks.

By using MA, fine microstructure and homogenous chemical composition of Fe based alloys can be achieved in solid state [10] while the solubility of alloying elements in Fe matrix can be increased $[11,12]$.

In Fe-Mn-Si SMAs the mechanism that governs the shape memory effect (SME) relays on stress induced formation of $\varepsilon$ (hexagonal close packed, hcp) martensite and on its thermally induced reversion to $\gamma$ (face centre cubic, fcc) austenite, on heating [13]. At low Mn content or at high deformation degrees, besides $\varepsilon$-hcp, a' (body

\footnotetext{
a Corresponding author: lgbujor@tuiasi.ro
}

centre cubic, bcc) martensite can be additionally induced by cooling or deformation [14].

In this paper, in order to investigate the structural differences between thermally-induced martensites observed in SMAs subjected to different processing routes, IM, PM and MA will be associated with hot rolling and coupled with two different solution treatment temperatures. The thermomechanical processing effects will be investigated during the reversion of thermally induced $\varepsilon$-hcp and $\alpha^{\prime}$-bcc martensite to $\gamma$-fcc austenite, by means of dynamic mechanical analysis (DMA) which are aimed to emphasize the correlations between storage modulus and internal friction variations with temperature and the characteristics of solution treated structures.

\section{Experimental}

\subsection{Powder sintering}

From elemental powders, two types of sintered specimens were obtained with the chemical composition $66 \mathrm{Fe}, 14$ $\mathrm{Mn}, 6 \mathrm{Si}, 9 \% \mathrm{Cr}$ and $5 \mathrm{Ni}$ (mass. \%) as previously detailed [15]. The two groups were designated as: (i) $0 \_M A$ obtained from as-blended elemental powders and (ii) 50 MA comprising 50 vol. \% fraction of mechanically alloyed (MA) powders obtained after high energy ball milling under argon atmosphere [12] for the duration of $4 \times 3.6 \mathrm{ks}$, which enabled optimal densification 
of compacted samples [16]. After pressing (500 MPa) and sintering (under argon atmosphere at $1423 \mathrm{~K}$ for $2 \times$ $3.6 \mathrm{ks})$, in order to further increase specimens compactness, six consecutive hot rolling passes were performed at $1373 \mathrm{~K}$, without allowing the billets to cool down to room temperature (RT), until reaching a thickness of $1 \mathrm{~mm}$ [17].

Hot rolling was performed with an experimental setup, comprising a tubular electric furnace and flat cylinders roller, which seized the billets when being pushed out the furnace, by a long flat-head rod [18]. With this procedure specimens' porosity degree decreased from $16.85 \%$ at $0 \_$MA to $2.51 \%$ at 50 MA.

Apparent density was accurately determined by hydrostatic weighing [19]. Hot-rolled lamellar specimens were machined, so as to remove surface oxide layers, and rectangular specimens $\left(4 \times 25 \mathrm{~m}^{-3}\right.$ were cut by spark erosion, before being solution treated at two different temperatures 973 and $1273 \mathrm{~K} /$ held $300 \mathrm{~s}$ and water quenched [20].

\subsection{Casting and hot working}

IM samples, with the same chemical composition as PM samples, were prepared in a FIVES CELES levitation furnace with inert atmosphere, with $25 \mathrm{~kW}$ power, melting temperature above $2273 \mathrm{~K}$, primary vacuum $10^{-8}$ $\mathrm{MPa}$ and secondary vacuum $3 \times 10^{-12} \mathrm{MPa}$. The material subjected to melting was placed in a copper cup-shaped crucible under vacuum. The alloy under investigation was received in the form of ingots with diameter of approx. $18 \times 10^{-3} \mathrm{~m}$, length of $35 \times 10^{-3} \mathrm{~m}$ and weight of $150 \times$ $10^{-3} \mathrm{~kg}$. From these ingots, $5 \times 10^{-3} \mathrm{~m}$-thick samples were cut in order to be plastically deformed by hot rolling and solution treated according to the above mentioned procedure. For simplicity reasons these samples are designated as $14 \mathrm{Mn}$.

\subsection{Microstructural characterization dynamo-mechanical analysis}

and

The microstructure of $0 \mathrm{MA}, 50 \mathrm{MA}$ and $14 \mathrm{Mn}$ specimens was observed, after appropriate metallographic preparation [21], using a SEM-VEGA II LSH TESCAN microscope, coupled with an EDX-QUANTAX QX2 ROENTEC detector. The average diameter of crystalline grains, of each of the nine different specimens, was statistically determined by means of OptikaView software.

$\mathrm{X}$-ray diffraction (XRD) patterns were recorded on the significance region $2 \theta=30 \ldots 100^{\circ}$, using an Expert PRO MPD diffractometer with $\mathrm{Cu} \mathrm{K}_{\alpha}$ radiation. Corresponding crystallographic databases were used for the identification of the three above mentioned metallographic phases, $\alpha$-bcc, $\gamma$-fcc and $\varepsilon$-hcp. Dynamomechanical analysis (DMA) tests were performed by means of a device type DMA 242 Artemis NETZSCH, with force resolution of $0.0005 \mathrm{~N}$, amplitude range: \pm 0.1 up to $240 \mu \mathrm{m}$ and amplitude resolution: $0.0005 \mu \mathrm{m}$. A specimen holder type three-point bending was used and a maximum dynamic force of $12 \mathrm{~N}$.

\section{Experimental results and discussion}

The SEM microstructure of $0 \_M A, 50 \_M A$ and $14 M n$ hot rolled specimens, is presented in Fig. 1.
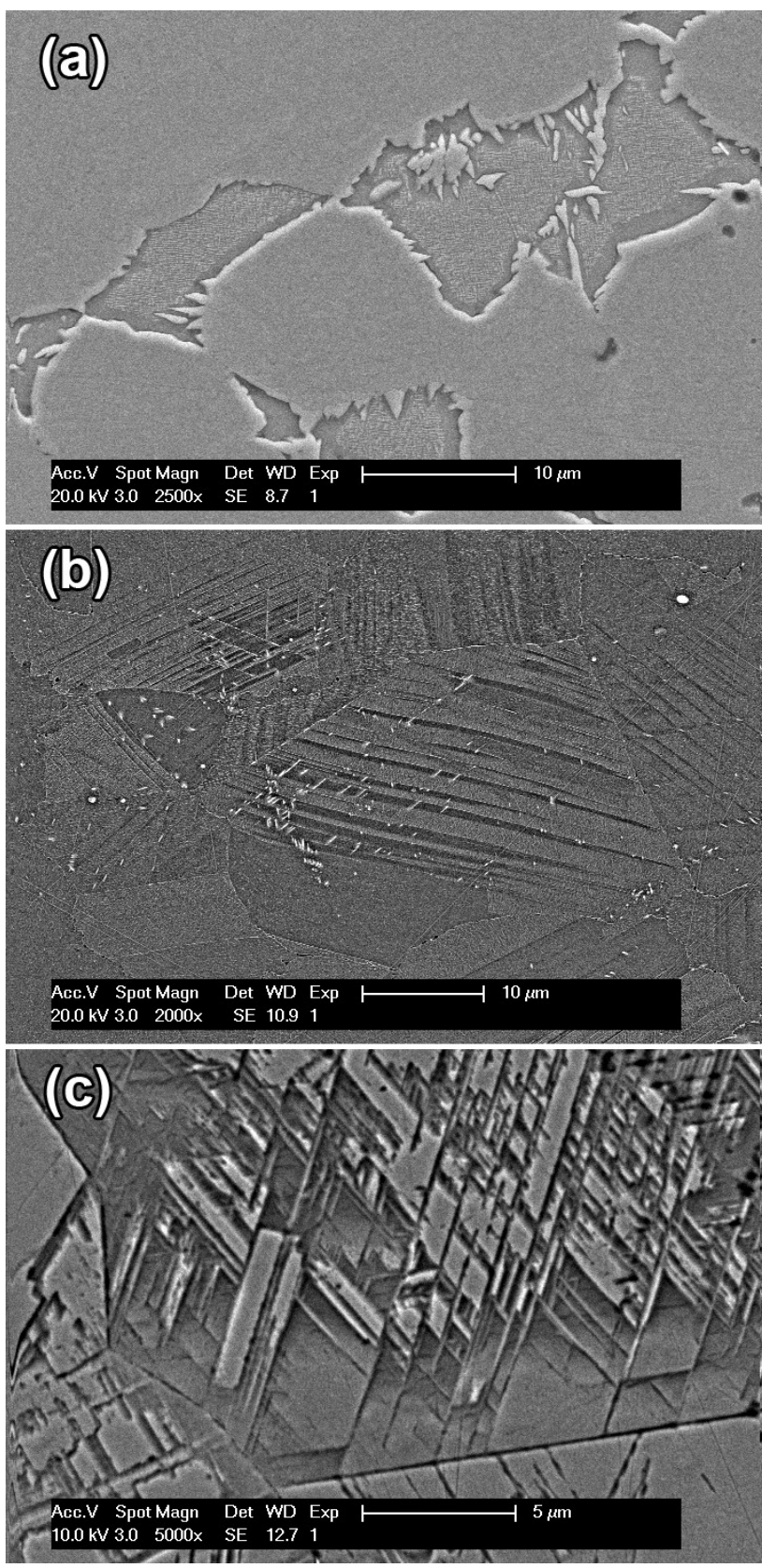

Figure 1. SEM micrographs illustrating the initial structure, after hot rolling, of (a) $0 \_M A$, (b) 50_MA and (c) $14 \mathrm{Mn}$

It is clearly seen that, among PM specimens, only the one with $50 \%$ MA fraction presents a martensitic structure, Fig.1(b), while in Fig.1(c) specimen 14Mn revealed a more complex martensitic structure, with more martensite plate variants that enable to observe the socalled "triangular morphology" of $\varepsilon$-hcp martensite, due to its habit planes of $\{111\}_{\gamma}$ type [22]. These observations suggest that hot rolling is more beneficial for the $14 \mathrm{Mn}$ then for PM specimens, from the point of view of martensite formation. On the other hand, hot rolling caused larger grains in IM specimens, as compared to PM ones. This difference could originate from the large 
number of barriers formed by grain boundaries, existing in PM specimens, which prevent the deformation of crystalline grains. Thus, in initial state, the average grain size of the specimens was $17.8 \mu \mathrm{m}$ for $0_{-} M A$ and $50_{-} M A$ and $74.4 \mu \mathrm{m}$ for $14 \mathrm{Mn}$.

The next two series of micrographs emphasize the effects of two different solution treatment temperatures on the microstructures of the three specimens under study. Thus, Fig.2 displays the typical SEM micrographs of $0_{-} M A, 50 \_M A$ and $14 M n$ specimens solution treated at $973 \overline{\mathrm{K}}$
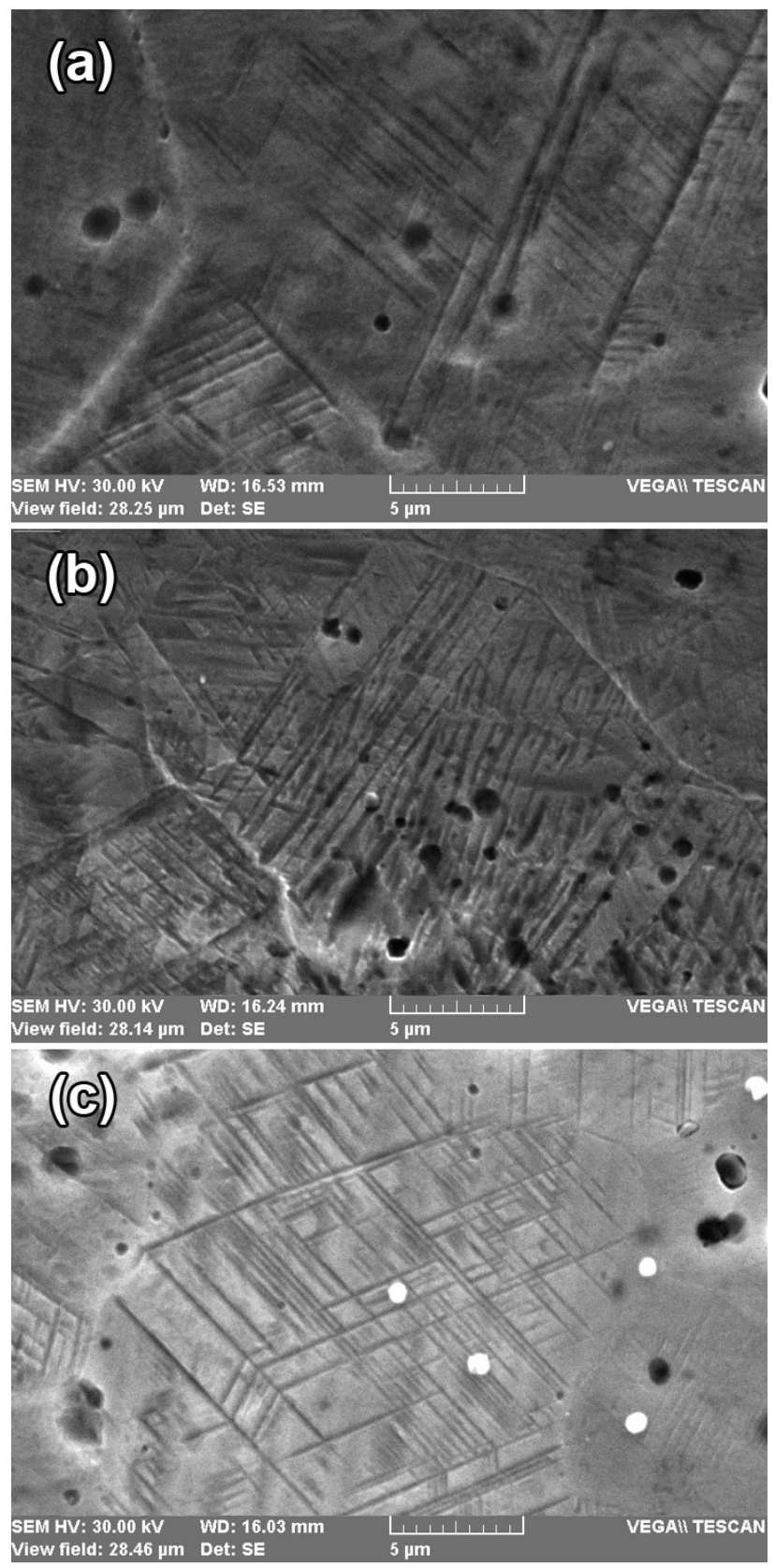

Figure 2. SEM micrographs illustrating the structure of the specimens solution treated at $973 \mathrm{~K}$ (a) $0 \_M A$, (b) 50_MA and (c) $14 \mathrm{Mn}$

It seems that more martensite was formed, especially in PM specimens where a larger quantity of plate variants is observed. On the other hand, in $14 M n$ specimen, a refinement of martensite plates is noticeable. After solution treatment at $973 \mathrm{~K}$, the average grain size of the specimens was $20.4 \mu \mathrm{m}$ for $0 M A, 18 \mu \mathrm{m}$ for $50 M A$ and $29.4 \mu \mathrm{m}$ for $14 \mathrm{Mn}$, where it can be assumed that grain size decreased due to recrystallization.

Increasing the heat treatment temperature to $1273 \mathrm{~K}$ led to the formation of finer preferentially oriented martensite variants throughout the observed field, as shown in Fig. 3. On the other hand, in the $14 M n$ specimen, applying this solution treatment resulted in wider martensite plates, which is not beneficial to shape memory effect [23]. After solution treatment at $1273 \mathrm{~K}$, the average grain size of the specimens was $24.6 \mu \mathrm{m}$ for 0_MA, $20.6 \mu \mathrm{m}$ for 50_MA and $40.3 \mu \mathrm{m}$ for $14 \mathrm{Mn}$.
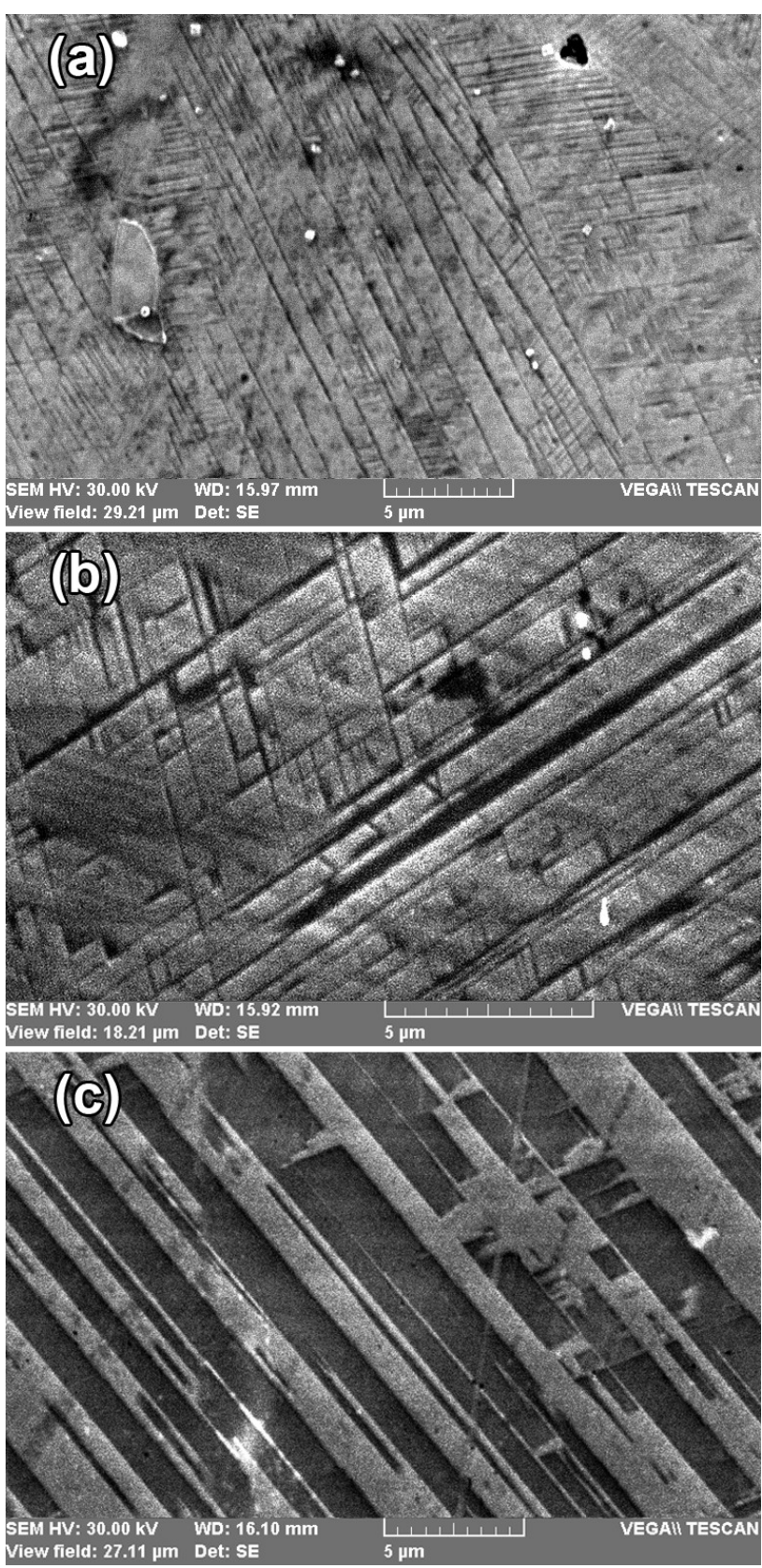

Figure 3. SEM micrographs illustrating the structure of the specimens solution treated at $1273 \mathrm{~K}$ (a) $0 \_M A$, (b) 50_MA and (c) $14 \mathrm{Mn}$

Considering SEM observations, it can be suggested that applying a solution treatment was beneficial for both 
type of samples. The $973 \mathrm{~K}$ temperature was favourable for the IM specimen because it refined the hot rolled structure while in PM specimens more martensite variants were formed. Increasing solution treatment temperature to $1273 \mathrm{~K}$ widened the martensite plates in IM sample, which is not desirable, but in PM samples produced finer preferentially oriented martensite variants.

In order to ascertain the presence of $\varepsilon$-hcp and $\alpha$ '-bcc thermally induced martensites and to corroborate it with the SEM observations, the specimens were further subjected to XRD analysis and the results are summarized in Fig. 4.
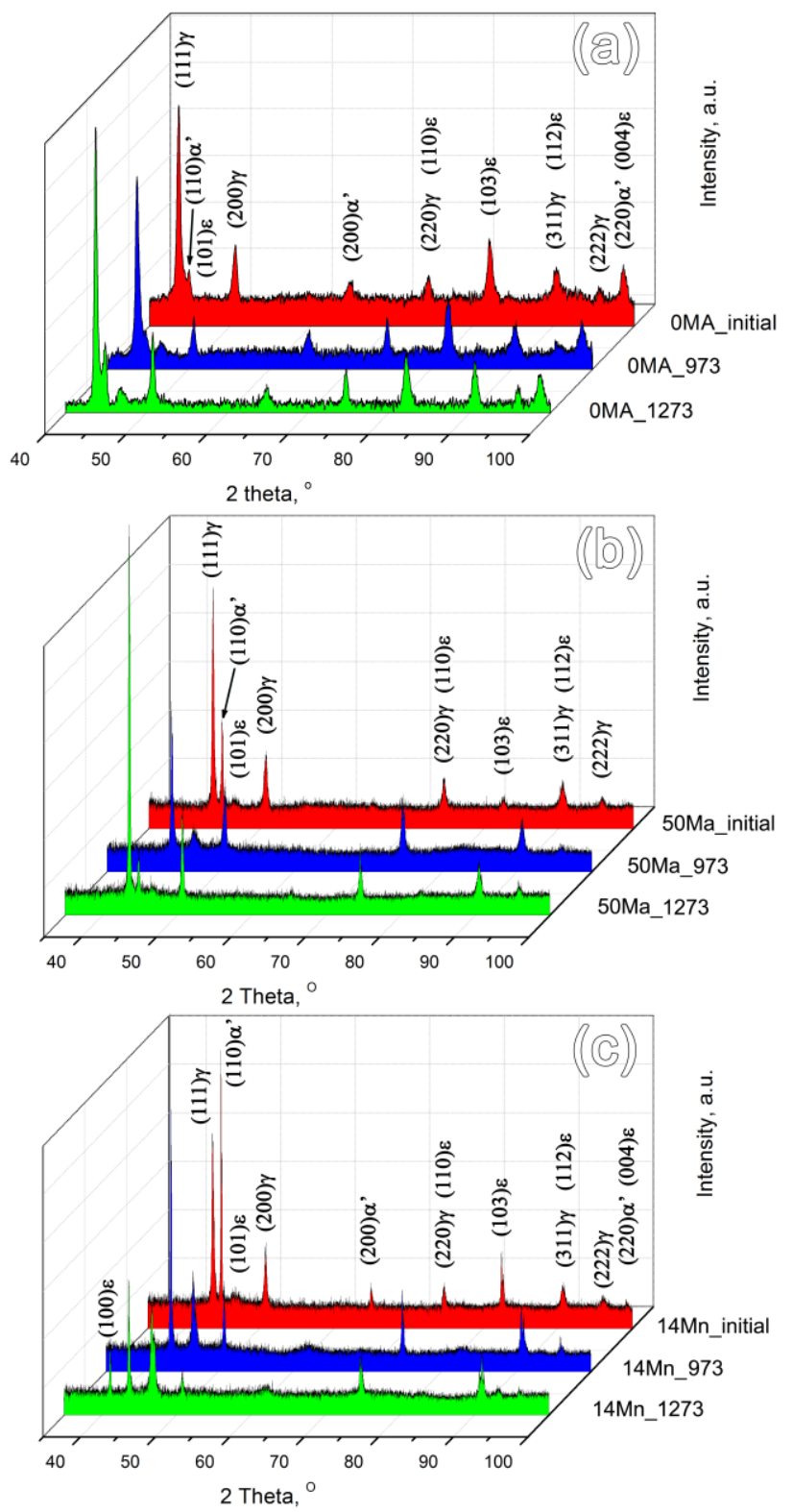

Figure 4. XRD patterns for the specimens in hot rolled (initial) and solution treated states at $973 \mathrm{~K}$ and $1273 \mathrm{~K}$ : (a) $0 \_M A$, (b) 50_MA and (c) $14 \mathrm{Mn}$

In Fig.4(a), the XRD pattern of $0_{-} M A$ hot rolled specimen, designated as "OMA_initial", does not present the main diffraction maximum, $(101)_{\varepsilon}$, of $\varepsilon$-hcp martensite, but reveals a small principal peak (110) ${ }_{\alpha}$, corresponding to the main closed-packed plane of $\alpha^{\prime}$-bcc martensite. This situation confirms the structure shown in the SEM micrograph from Fig.1(a), where no martensite plates are noticeable. As an effect of solution treatment, the main diffraction maxima, $(101)_{\varepsilon}$ and $(110)_{\alpha}$, became visible, being more intense after $1273 \mathrm{~K}$-treatment, thus confirming the structures of Fig.3(b) and (c).

In the case of specimens 50_MA and $14 M n$, in hotrolled condition, the martensite plates observed in the microstructure can be associated with the presence of main diffraction maxima $(101)_{\varepsilon}$ and mostly $(110)_{\alpha}$, from XRD patterns of Fig.4(b) and (c), respectively. The higher density of martensite plates, observed in Figs. 2 and 3 as an effect of applying the solution treatments, is reflected by the higher values of intensity for the main diffraction maxima of the two phases, in Fig.4(b) and (c).

Another aspect that can be observed from the XRD patterns is the evolution of $\alpha^{\prime}$-bcc martensite as an effect of solution treatment. In PM specimens, both in hotrolled and solution treated states, there is definitely a certain amount of $\alpha^{\prime}$-bcc martensite, which is undesired from the point of view of shape memory properties, since it suppresses crystallographic reversibility of the $\varepsilon$-hcp martensite to $\gamma$-fcc austenite [24]. On the other hand, in $14 M n$ specimen, no $\alpha$ '-bcc martensite could be identified as an effect of solution treatment, since the diffraction peaks of both $(110)_{\alpha}$, and $(200)_{\alpha}$, are missing.

Some of the diffraction maxima are broader peaks that could be indicative for either small crystallite size along the direction normal to the specified planes or for distortions of the crystal structure. This is the case of $\varepsilon$ hcp martensite in Fig.4(a) that was associated with broad diffraction maxima, at specimen $0_{-} M A$.

Aiming to confirm the reversion of thermally induced martensites to austenite, on heating, DMA tests were performed and the results are summarized in Fig. 5, where the variation curves were smoothened by means of PROTEUS software, which controls the functioning of DMA device.

At Fe-Mn-Si SMAs, internal friction ( $\tan d$ ) peaks are accompanied by storage modulus decreases during heating [25], due to the fact that the modulus of $\varepsilon$-hcp phase is higher than that of $\gamma$-fcc phase [26]. On the other hand, there is always a discrepancy between the temperature of the starting point of modulus decreasing and that of the beginning of internal friction peak [27]. Nevertheless, when two internal friction maxima occur, during heating of Fe-Mn-Si based SMAs, the former, located at lower temperatures, can be ascribed to $\alpha^{\prime}$-bcc $\rightarrow \gamma$-fcc reversion and the latter, located at higher temperatures, to $\varepsilon$-hcp $\rightarrow \gamma$-fcc reverse martensitic transformation [28]. The critical temperatures $\mathrm{A}_{\mathrm{p}}{ }^{\text {' }}$ and $\mathrm{A}_{\mathrm{p}}{ }^{\varepsilon}$, together with the values of their respective tan $\mathrm{d}$ maxima, were determined for all of the specimens, since they give the positions of the two reverse martensitic transformations. Another important characteristics are the increase in storage modulus, $\Delta \mathrm{E}^{\prime}$, and its maximum value, $E_{\text {max }}^{\prime}$, which can be associated with the antiferromagnetic transition of $\gamma$-fcc austenite, occurring during heating, at Néel temperature [27]. It is known that a steep transition occurs during heating, from antiferromagnetic to paramagnetic state, being accompanied by increases of storage modulus [29]. The 
results are summarized in Table 1.

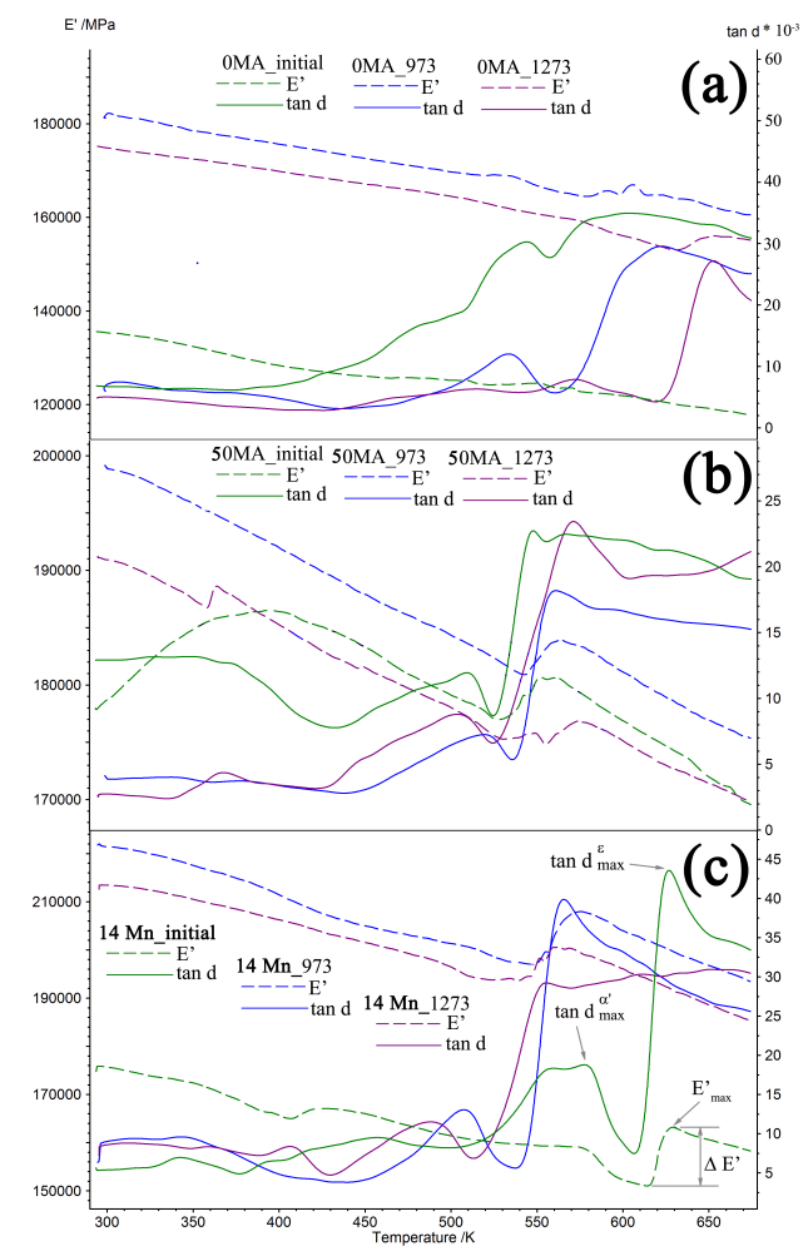

Figure 5. DMA thermograms illustrating the variation of storage modulus and internal friction with temperature during heating: (a) $0 \_M A$, (b) $50 \_M A$ and (c) $14 M n$

Table 1. Characteristic parameters determined from DMA thermograms of Fig.5, associated with reverse martensitic transformations occurring during heating

\begin{tabular}{|c|c|c|c|c|c|c|c|}
\hline Specimen & State & $\begin{array}{l}\Delta \mathrm{E}^{\prime}, \\
\mathrm{GPa}\end{array}$ & $\begin{array}{l}E_{\text {max }}^{\prime}, \\
\text { GPa }\end{array}$ & $\begin{array}{l}A_{p}{ }^{\alpha}{ }^{\prime} \\
K\end{array}$ & $\operatorname{tand}{ }^{\alpha^{\prime}}{ }_{\text {max }}$ & $\begin{array}{l}\mathrm{A}_{\mathrm{p}}{ }^{2} \\
\mathrm{~K}\end{array}$ & $\operatorname{tand}^{\varepsilon}{ }_{\text {max }}$ \\
\hline \multirow{3}{*}{ O_MA } & Initial & - & - & 544 & 0.030 & 603 & 0.035 \\
\hline & $973 \mathrm{~K}$ & - & - & 533 & 0.012 & 622 & 0.030 \\
\hline & $1273 \mathrm{~K}$ & - & - & 572 & 0.008 & 652 & 0.027 \\
\hline \multirow{3}{*}{ 50_MA } & Initial & 4 & 181 & 510 & 0.012 & 549 & 0.023 \\
\hline & $973 \mathrm{~K}$ & 3 & 184 & 520 & 0.007 & 562 & 0.018 \\
\hline & $1273 \mathrm{~K}$ & 2 & 177 & 505 & 0.009 & 572 & 0.024 \\
\hline \multirow{3}{*}{$14 M n$} & Initial & 12 & 163 & 578 & 0.019 & 627 & 0.044 \\
\hline & $973 \mathrm{~K}$ & 11 & 208 & 507 & 0.013 & 566 & 0.040 \\
\hline & $1273 \mathrm{~K}$ & 7 & 201 & 488 & 0.012 & 556 & 0.029 \\
\hline
\end{tabular}

It is noticeable, from Fig.5, that storage modulus E', had the lowest values in initial condition, for the specimens in hot rolled state, while the highest values were obtained at the specimens solution treated at $973 \mathrm{~K}$. In contrast to $0 \_M A$, where no marked variations of $\mathrm{E}$ ' are noticeable at $50 \_M A$ and $14 M n$ specimens, the increase in storage modulus, $\Delta \mathrm{E}^{\prime}$, reached a maximum of $12 \mathrm{GPa}$ at $14 \mathrm{Mn}$ initial. $\Delta \mathrm{E}^{\prime}$ ' experienced a decreasing tendency, with the application of solution treatment and with the augmentation of its maximum heating temperature. From the point of view of the two tan d variations, both internal friction maxima tend to decrease with the application of solution treatment and with the augmentation of its maximum heating temperature. The maximum internal friction values were obtained after hot rolling and reached 0.03 for the maximum associated with the reversion of $\alpha^{\prime}-\mathrm{bcc}$, at $0 \_M A$ and 0.044 for the peak ascribed to $\varepsilon$-hcp reversion, at $14 M n$. The temperatures of this peak, $\mathrm{A}_{\mathrm{p}}^{\varepsilon}$, had steady tendency to increase at PM specimens and to decrease at $14 M n$, with the application of solution treatment and with the augmentation of its maximum heating temperature.

Considering the strong dependence of martensitic transition temperatures on chemical composition and thermo-mechanical treatments, as well as the small temperature difference between $\mathrm{A}_{\mathrm{p}}{ }^{\prime}$ and $\mathrm{A}_{\mathrm{p}}{ }^{\varepsilon}$ peaks, thermal expansion experiments were performed, in order to confirm the assumed transformation succession $\alpha$ 'bcc $+\varepsilon$-hcp $+\gamma$-fcc $\rightarrow \varepsilon$-hcp $+\gamma$-fcc $\rightarrow \gamma$-fcc. An example is given in Fig.6.

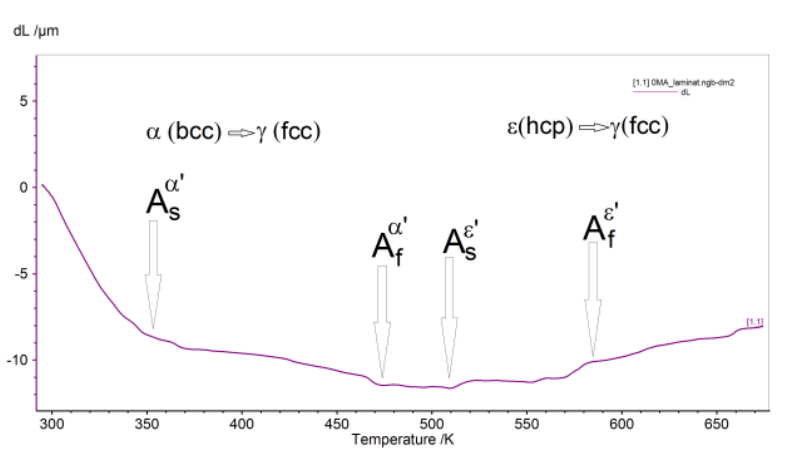

Fig.6 Example of thermal expansion curve of specimen $0 \_M A$ in initial state, illustrating the $\alpha^{\prime}$-bcc $+\varepsilon$-hcp $+\gamma$-fcc $\rightarrow \varepsilon$-hcp + $\gamma$-fcc $\rightarrow \gamma$-fcc transformation succession.

The example shown in Fig.6 illustrates a series of shrinkage and expansion phenomena. The shrinkages, located at lower temperatures, can be associated with $\alpha$ 'bcc $\rightarrow \gamma$-fcc transition which is accompanied by a compactness increase. This is why the starting point of shrinkage was designated as $\mathrm{A}_{\mathrm{s}}^{\alpha^{\prime}}$ and the end as $\mathrm{A}_{\mathrm{f}}^{\alpha^{\prime}}$. On the other hand, after the reversion of $\alpha^{\prime}$-bcc martensite to $\gamma$-fcc austenite no more shrinkage is noticeable. Yet, the expansion occurred with different variation rates, since $\gamma$ fcc austenite has a larger number of close-packed plane families, as compared to $\varepsilon$-hcp martensite. For this reason, the starting point of fast thermal expansion was designated as $\mathrm{A}_{\mathrm{s}}{ }^{\varepsilon}$ and the end with $\mathrm{A}_{\mathrm{f}}^{\varepsilon}$.

\section{Summary and conclusions}

A comparative study was performed between IM and PM specimens of $66 \mathrm{Fe}, 14 \mathrm{Mn}, 6 \mathrm{Si}, 9 \% \mathrm{Cr}$ and $5 \mathrm{Ni}$ (mass. \%) SMA, in three processing states: (i) hot rolling, (ii) solution treated at $973 \mathrm{~K}$ and (iii) solution treated at 1273 K. By corroborating SEM, XRD and DMA observations, the following conclusions can be drawn:

- at PM specimens, the formation of thermally induced martensite was enhanced both by MA and the increase of solution treatment temperature; 
- hot-rolling has been more effective, from the point of view of the formation of thermally-induced martensite, in the case of IM specimens;

- at IM specimens, where large amounts of $\alpha^{\prime}$-bcc were observed after hot-rolling, solution treatment caused the disappearance of this martensite;

- the application of solution treatment and the augmentation of its maximum heating temperature had the tendency to cause: (i) the decrease of modulus hardening, $\Delta \mathrm{E}^{\prime}$, at specimens 50_MA and $14 M n$ and (ii) the diminution of internal friction maxima associated with both $\alpha^{\prime}$-bcc and $\varepsilon$-hcp reversion to austenite;

- at hot-rolled IM specimens the highest values were obtained for modulus hardening, $\Delta \mathrm{E}^{\prime}=12 \mathrm{GPa}$ and for the internal friction maximum associated with $\varepsilon$ hep reversion to austenite, tand ${ }^{\varepsilon}{ }_{\max }=0.044$.

\section{Acknowledgements}

This research work was supported by UEFISCDI through project code PN-II-ID-PCE-2012-4-0033, Contract 13/2013.

\section{References}

1. A. Sato, E. Chishima, K. Soma, T. Mori, Acta Metall 30, 1177 (1982)

2. H. Otsuka, H. Yamada, T. Maruyama, H. Tanahashi, S. Matsuda, M. Murakami, ISIJ Int 30, 674 (1990)

3. Y. Moriya, H. Kimura, S. Ishizaki, S. Hashizume, S. Suzuki, H. Suzuki, T. Sampei, J. Phys. III 1, 433 (1991)

4. J. Nakano, P. J. Jacques, CALPHAD 34, 167 (2010)

5. B. C. Maji, M. Krishnan, Phys. Proced. 10, 111 (2010)

6. T. Matsumiya, CALPHAD 35, 627 (2011)

7. T. Kirindi, E. Güler, M. Dikici, J Alloy Compd 433, 202 (2007)

8. H. Berns, W. Theisen, Ferrous Materials. Steel and Cast Iron (190 Springer 2008)

9. Y. Suzuki, in Shape Memory Materials, (K. Otsuka, C.M. Wayman, eds.), Cambridge, pp. 145-147 (1998)
10. Q. He, C. Jia, J. Meng, Mat Sci Eng A 428, 314 (2006)

11. A. Hightower, B. Fultz, R.C. Bowman Jr, J Alloys Compd 252, 238 (1997)

12. A. Umut Söyler, Burak Özkal, Leandru G. Bujoreanu, TMS 1, 577 (2011)

13. T. Maki, K. Otsuka, C. M. Wayman (Eds.) (Cambridge, University Press, p. 117, 1998)

14. L. Bracke, G. Mertens, J. Penning, B. C. De Cooman, M. Liebeherr, N. Akdut, Metall Mater Trans A 37A, 307 (2006)

15. A. Umut Söyler, Burak Özkal, Leandru G. Bujoreanu, J. Mater. Eng. Perform. 23, 2357 (2014).

16. A. U. Söyler, B. Özkal, L. G. Bujoreanu, TMS 3, 785 (2010).

17. B. Pricop, B. Özkal, U. Söyler, J. Van Humbeeck, N. M. Lohan, M. G. Suru, L.-G. Bujoreanu, Optoelectron Adv Mat 8, 247 (2014).

18. L. G. Bujoreanu, V. Dia, S. Stanciu, M. Susan, C. Baciu, Eur Phys J Special Topics 15, 158 (2008)

19. H. A. Bowman and R. M. Schoonover, J Res Natl Inst Stan- C. Eng. Instr., 71(3), 179-198, (1967).

20. I. P. Spiridon, B. Pricop, M. G. Suru, A. L. Paraschiv, N. M. Lohan, L-G. Bujoreanu, J Optoelectron Adv M 15, 730 (2013).

21. B. Pricop, U. Söyler, B. Özkal, N. M. Lohan, L. Paraschiv, M. G. Suru, L.-G. Bujoreanu, Mater Sci Forum 738-739, 237 (2013).

22. S. Kajiwara, Mater. Sci. Eng. A, 273-275, 1999, 6788

23. K. Ogawa, T. Sawaguchi, T. Kikuchi, S. Kajiwara, Mater T JIM 48, 869 (2007)

24. X. H. Min, T. Sawaguchi, K. Ogawa, T. Maruyama, F. X. Yin and K. Tsuzaki, Mat. Sci. Eng. A, 528, 5251 (2011)

25. V. G. Gavriljuk, P. G. Yakovenko, K. Ullakko, Scripta Mater., 38, 931 (1998)

26. J. F. Wan, S. P. Chen, T. Y. Hsu, Y. N. Huang, Mat. Sci. Eng. A, 438-440, 887 (2006)

27. X. Wu, T. Y. Hsu, Mater. Char., 45, 137 (2000)

28. T. S. Chou, H. C. Lin, K. M. Lin, S. K. Wu, Scripta Mater., 42, , 445 (2000)

29. O. Bouaziz, S. Allain, C. P. Scott, P. Cugy, D. Barbier, Curr. Opin. Solid. St. M., 15, 141 (2011). 